\title{
Properties of a Triazolopyridine System as a Molecular Chemosensor for Metal Ions, Anions and Amino Acids.
}

Mimoun Chadlaoui, Belén Abarca, Juan Aguilar, Ricardo Aucejo, Rafael Ballesteros, Enrique García-España, Carmen Ramírez de Arellano

Supplementary Materials Includes:. Figure S1.- Job Plot for the system $\mathrm{Cu}^{2+}-(\mathbf{1})$. Figure S2.- Plot of the fluorescence emission intensity vs. the phosphate concentration and the fitting curve. Figure S3.- Plot of the fluorescence emission intensity vs. the sulphate concentration and the fitting curve. Figure S4.- Plot of the fluorescence emission intensity vs. the chloride concentration and the fitting curve. Table S1. ${ }^{13} \mathrm{C}$ NMR $\delta$ values of ligand 1 and complex 2 in DMSO. 


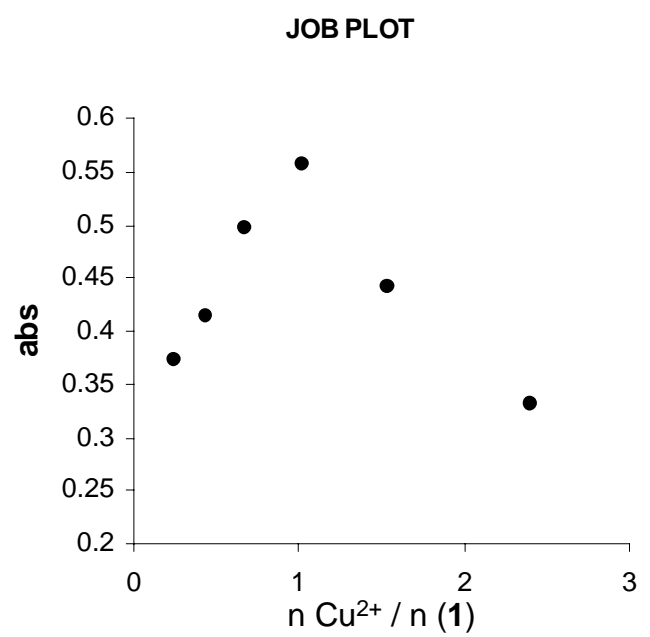

Figure S1.- Job Plot for the system $\mathrm{Cu}^{2+}-(\mathbf{1})$ 


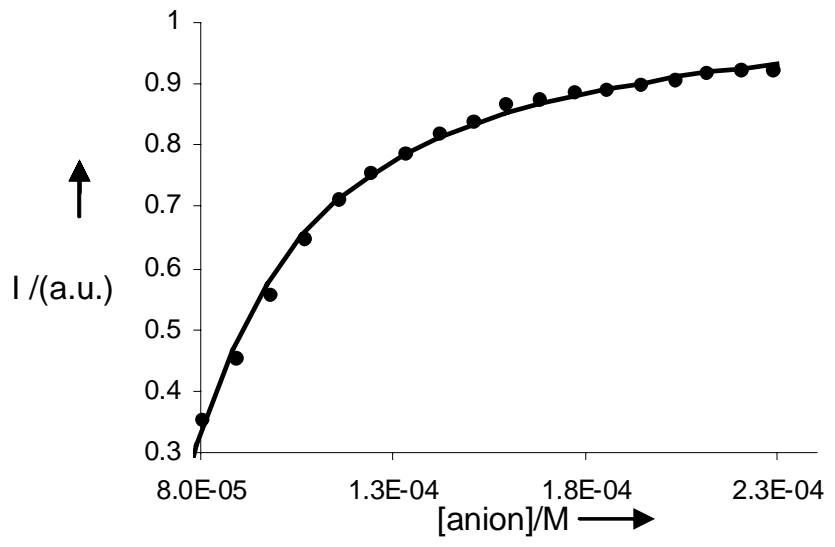

Figure S2.- Plot of the fluorescence emission intensity vs. the phosphate concentration and the fitting curve. 


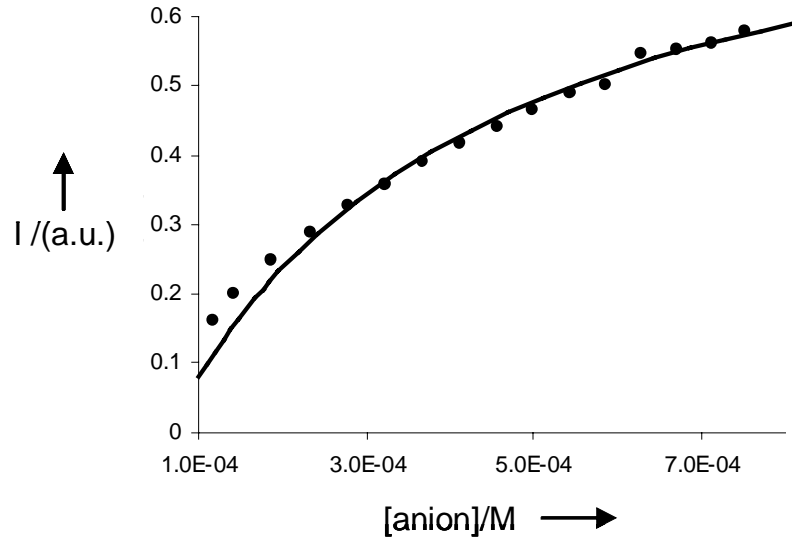

Figure S3.- Plot of the fluorescence emission intensity vs. the sulphate concentration and the fitting curve. 


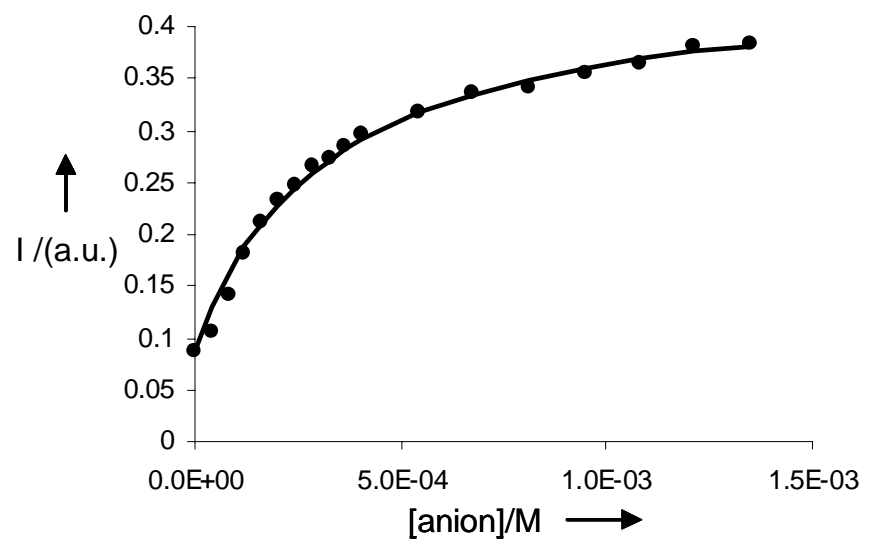

Figure S4.- Plot of the fluorescence emission intensity vs. the chloride concentration and the fitting curve.

Table S1. ${ }^{13} \mathrm{C}$ NMR $\delta$ values of ligand 1 and complex 2 in DMSO.

\begin{tabular}{|c|c|c|c|c|c|c|c|c|c|c|c|}
\hline & $\mathbf{C 5}$ & $\mathbf{C 4}$ & $\mathbf{C 6}$ & $\mathbf{C 5}$ & $\mathbf{C 4}$ & $\mathbf{C 3}$ & $\mathbf{C 6} \mathbf{C 5}^{\prime}$ & $\mathbf{C 5}$ & $\mathbf{C 4} \mathbf{C 3}^{\prime}$ & $\mathbf{C 3}$ & $\mathbf{C H}_{\mathbf{3}}$ \\
\hline $\mathbf{1}$ & 122.0 & 117.0 & 149.0 & 126.0 & 139.0 & 126.0 & 150.0 & 126.5 & 138.0 & 124.0 & 10.5 \\
\hline $\mathbf{2}$ & 122.0 & 120.0 & 150.0 & 127.0 & 140.0 & 127.0 & 150.0 & 127.0 & 140.0 & 125.0 & 11.0 \\
\hline$\Delta \boldsymbol{\delta}$ & 0 & -3.0 & -1 & -1 & -1 & -1 & 0 & -0.5 & -1 & -1 & -0.5 \\
\hline
\end{tabular}

